\title{
Contextual Knowledge in Design: the SisPro project
}

\author{
Ricardo Naveiro* — Patrick Brézillon** — Romir Souza Filho*** \\ * Universidade Federal do Rio de Janeiro/COPPE - Programa de Engenharia de \\ Produção, Centro de Tecnologia, Caixa Postal 68507, 21945-970, Rio de Janeiro \\ ricardo@pep.ufrj.br \\ ** Université Pierre et Marie Curie/Laboratoire d'Informatique de Paris 6, \\ Case Courrier 169, 4 place Jussieu, F-75252 Paris cedex 05 \\ Patrick.Brezillon@lip6.fr \\ *** Universidade Federal de Juiz de Fora - Departamento de Fundamentos \\ de Projeto, Rua Benjamin Constant 790, 36015-400, Juiz de Fora \\ romir@engprod.ufjf.br
}

ABSTRACT: This paper describes an ongoing research at the step of the development of the SisPro project, a web-based environment for distributed architecture/engineering/ construction teamwork. The project aims at the improvement teamwork performance allowing participants to team up and cooperate in projects by interacting remotely in a virtual environment. The SisPro environment takes advantage of information technology to permit people geographically apart to maintain a shared conception of a problem, in which knowledge is learned in applied situations. The notion of context in the acquisition of these types of knowledge is explored and it is explained how SisPro enables participants to structure contextual knowledge and partially share their individual's tacit knowledge. The paper concludes by highlighting some of SisPro features and adressing some issues for future development.

RÉSUMÉ: Ce papier présente les résultats d'une recherche en cours sur le développement du projet SisPro qui est un environnement basé sur le web pour une équipe travaillant sur l'architecture, l'ingénierie et la construction distribuée. Le but du projet est d'améliorer les performances de l'équipe pour permettre aux spécialistes de différentes disciplines d'interagir directement ou indirectement dans un environnement virtuel. L'environnement tire avantage des technologies de l'information actuelles permettant à des personnes situées dans des zones géographiques différentes de maintenir une conception partagée du problème en cours de traitement, et dans laquelle les connaissances sont apprises dans des situations concrètes. En conclusion, ce papier souligne certaines des caractéristiques du projet SisPro et précise quelques pistes pour son developpement à venir.

KEYWORDS: cooperation in design, A/E/C sector, teamwork, context.

MOTS-CLÉS : coopération en dessin, secteur bâtiment, travail en groupe, contexte.

Document numérique. Volume 5 - n 3-4/2001, pages 115 à 134 


\section{Introduction}

This paper describes the SisPro project, a project that envisages the improvement of design activities in the Architecture, Engineering \& Construction (AEC) sector. The SisPro project encompasses a computer environment to aid a design team in a project and some experiments to evaluate the improvements achieved by teams in real design situations. Experiments will be made with professionals and with engineering students as well. The SisPro computer environment aims at supporting cooperation activities and learning processes that are launched when working in a team.

Design is a complex activity. Problems faced by architects and engineers are ill structured and incomplete. Design is a knowledge-based process in which data, information and knowledge are processed simultaneously by a team of architects and engineers involved during the lifecycle of a product. Design practice encompasses a series of creative activities such as artifact planning, product development, product synthesis and problem solving. Moreover, design involves an incremental learning process as an intrinsic part of designers' activities. The design process involves a typical sequence of steps in which the degree of uncertainty diminishes as the work progress, and the design progression can be viewed as a collection of successive states in which abstract ideas arrive to an embodied product.

Design is also seen as something with a great deal of innovation. However, in companies, the current design practice is mostly concentrated in the modifications and in the incremental improvements of current products. Some projects have a high innovative content, but most of the projects follow a different pattern, where innovation is not high. In these cases the artifact structure is unknown and emerges from the design activity itself. The design process is carried out in a planned way, in order to keep design activities consistent with the goals.

The classes of design commonly found in industry are adaptative design and variant design, which involve the use of known strategies, or established design plans to arrive to new solutions. In these cases, the problem decomposition strategy and some classes of solution are already known. In other words, the initial perception of the product structure is known and the disciplines needed to solve the design problems are already identified, as, for example, the case of designing townhouses and apartment-buildings. However, there is always some particularity in the design constraints, and different types of knowledge are always required in the design activity.

Learning and design are closely related activities where finding a new solution involves the search and acquisition of new knowledge. At preliminary steps of the design progression, a way to understand and to structure a design problem is to retrieve former design cases and design plans to form an abstract knowledge that can be further explored, in the spirit of case-based reasoning (Tang, 2001; Kolodner, 1983). It is an inductive learning process that includes assimilation of new knowledge in a body of known and organized knowledge for future use. The 
information gathered in former projects is reshaped and reorganized, allowing engineers and architects to generalize and abstract ideas that are explicit in particular situations to use them in analogous situations.

Both learning and design are social processes, as underlined by the literature on communities of practice (Brown and Duguid, 1999; Wenger, 1998) and on design science (Bucciarelli, 1994; Naveiro and Oliveira, 2001). In this way, design is considered much more effective communication and collaboration, an environment for negotiation and decision in which members have a shared understanding, knowing what is relevant to communicate and how to present information in useful ways.

Designing a product or a building involves the perception of the artifact structure that dynamically changes along the design progression, and also the translation of each state into the generation of new ideas. The artifact attributes captured by participants, and their interrelations, permit the clarification of the organization of design tasks accordingly with the design state and with the participant's role. The way in which participants capture artifact attributes is context-dependent because each person builds an interpretative context of the artifact that links their universe of specialization with the collective common goal. Participants think and work according to instrumental norms grounded in technical expertise. The object itself strongly influences how participants relate and identify the tasks to be accomplished (Bucciarelli, 1994).

On the other hand, the design of technological artifacts can be characterized as a cognitive activity. Many researchers of the communities of cognitive ergonomics and psychology try to understand the nature of design expertise and to evaluate computer tools for supporting the design process. This way of approaching the design activity enhances the intellectual activities of problem solving and the strategies used by designers to reduce the complexity of design tasks (Karsenty and Brézillon, 1995). Thus, the main issues addressed in this paper are the mental mechanisms of association, decomposition and prototyping and their relations with external representations of the artifact.

These two approaches in understanding the nature of the design process collective and individual - are complementary. The process of designing an artifact is normally conducted by a team of professionals. Each specialist plays a specific role within the team and, simultaneously, and is obliged to negotiate constraints and requirements with other specialists to arrive to feasible solutions. Considering computers to support design activities must take into account these two aspects of the design activity (Naveiro, 1997).

In the past, the role played by computer tools in the design process was restricted to make drawings, do calculations and make analysis. All these tasks were normally done after designers made their major decisions. At first, Computer-Aided Design (CAD) systems were used as a means to create drawings of an artifact, but they have evolved these last years. Nowadays, CAD systems follow the trend of incorporating knowledge into new applications. 
Modern CAD systems are feature - based and embody knowledge in some domains. This permits to make evaluations while designing, i.e., an engineer for example, when conceiving a mechanism, can verify spatial interference between two moving parts by simulating their movement. Assessing product manufacturability and assemblability is now common place in several commercial CAD systems. They can also be tailored to incorporate companies' current practices in their evaluation tasks. New generation of CAD systems can embody companies' current practices in the evaluation of new design ideas, verifying their preliminary feasibility. These new systems embody knowledge retrieved from former projects conveying relevant knowledge to designers, in a similar situation as reported by Zacklad and Grundstein (2001) explaining the process of capitalizing knowledge in enterprises.

In the latest years, some effort has been dedicated to develop computer tools to aid teamwork, and especially design teams. Companies are increasingly distributed worldwide and projects being assigned between companies and their suppliers. A series of "one-to-one" collaboration arrives when developing a project, and companies must coordinate and make compatible the exchange of data, information and knowledge between very different contexts. Moreover, there are geographical barriers that can be surpassed with this sort of computer tools. However, most systems developed to aid the design activity are still conceived as standalone ones, and they hardly help teamwork.

This article reports a research work on the development of cooperative systems to support design. We discuss the role played by cooperation and knowledge in the development of computer systems to support design teams. We start by reviewing in section 2 some characteristics of knowledge related to the design practice. In section 3, the topics of cooperation and learning are explored and focused in the theme of computer-supported cooperative work. Section 4 presents the design process in the building industry and highlights the design phase on which the paper focuses. In section 5, a web-based cooperative system applied to the building industry is presented - the SisPro project. The paper completes by highlighting the main features of SisPro, by remarking the challenges of CSCW, and by adressing future research to be done.

\section{Design and Knowledge}

Design is a knowledge-driven activity in which requirements and constraints are transformed in a product description. The design process involves a great deal of knowledge accumulated by engineers and technicians during their professional life. Knowledge sources vary from formal education to individual experience, including knowledge derived from similar cases. Defining a cognitive structure for a design problem and its solutions is a knowledge-based learning process that involves practical knowledge and theoretical assets as well. 


\subsection{Types of knowledge}

A progressive process of construction going back to data can define knowledge. Data is a set of symbols perceived by a person transformed to information in the interpretation of what is perceived. In this way, information is data with meaning. Thus, information is structured data with a semantic content expressible by natural language. Information is thus data with a meaning visible or understandable, something shareable and immediately usable by human beings based on their knowledge (Brézillon and Pomerol, 2001).

Engineers and architects use basically two types of knowledge when creating new products: procedural and declarative knowledge. The first one is a type of knowledge expressed by procedures in organizational life, while declarative knowledge refers to more descriptive knowledge represented by equations, logical relations, or agents in new programming languages. This subject takes us to the distinction between theory and practice or know how versus know that. Theory refers to domain models, causal explanations or rules that explain certain phenomenon, and types of knowledge normally acquired by formal education. Practical knowledge refers to something that can be acquired from people doing efficiently a given task (human experts).

The notion of "practicability" offers another possible way of analysis. This has been renewed by the study of "communities of practice" (Brown and Duguid, 1999) and (Smith and Farquhar, 2000). The notion of practical knowledge is particularly relevant in learning because it has been observed for centuries that some knowledge needs apprenticeship (i.e., practice) to be learnt whereas another does not require such practice (Clancey, 1995). This discussion matches the situation observed in people involved with conception, in which design knowledge cannot be assimilated without practice.

Explicit or declarative knowledge is easily shared whereas tacit knowledge is highly personal. Moreover, we would also distinguish between tacit knowledge that can be made explicit and tacit knowledge that cannot be made explicit, even if this later can be shared in a community of practice. This is the case of many handling skills in many craft jobs, and is also the case in teaching architecture and engineering by assigning projects to the students.

The distinction between tacit and explicit is also important whereas we believe that any kind of knowledge can be made explicit or implicit depending on the circumstances, the persons and the society. Learning and design are both social processes where the acquisition and validation of the "know how" are two central issues within a project team in which individual tacit knowledge must be shared and transformed in something understandable by participants. These movements between tacit and explicit knowledge are well known (Nonaka and Takeuchi, 1995), and Pomerol and Brezillon (2001) propose new insights on these differences by the introduction the notion of context. 


\subsection{Knowledge and context}

Context is an important issue in a number of domains (Brézillon, 1999), especially when investigating learning processes. From an engineering point of view, context can be seen as the collection of relevant conditions and surroundings influence that make a situation unique and comprehensible (Anderson, 1995). A person doing a task normally identifies which knowledge is relevant to do his job in his repertoire, i.e. the set of knowledge pieces accumulated along his working life. According to Brézillon \& Pomerol (1999) these knowledge pieces, which are judged related to a specific step of task accomplishment, constitute the contextual knowledge.

The authors also argue that, within a decision making process, a part of the contextual knowledge is invoked, structured and situated according to a given focus, thus reducing the universe of a search. This part is named the proceduralized context that is associated with the decision process at a given step or situation. In design, the reuse of knowledge abstracted from previous projects involves the building of an interpretative context of the former design situations to make them ready for use in a current task.

Another aspect of the proceduralization is that people use contextual knowledge into some functional knowledge or causal and consequential reasoning to anticipate the result of their own action. This functionalization, or proceduralization, obeys to the necessity of having a consistent explicative framework to anticipate the results of a decision or an action. This consistency is obtained by reasoning about causes and consequences in a given situation. This description matches the situations experienced by engineers or architects when looking ahead to the consequence of their design decisions.

Another proceduralization aspect is a kind of instantiation. This means that the contextual knowledge or background context needs some further specifications for perfectly fitting to the task at hand. This refinement and specialization brought to the contextual knowledge is also a part of the proceduralization process. This occurs when engineers and architects represent, say, their conceptions through the graphical representations of their ideas. The proceduralization process that takes place is within the individual, and the graphical representations express the proceduralized context represented on a piece of paper.

The relationship between these ideas and design situations is very close. When a design task is assigned to a student, his perception of the contextual knowledge is not straightforward, i.e., grabbing relevant knowledge from his repertoire is not easy for a novice. Design knowledge is built up incrementally on the basis of experience. The ability to deal with new cases is derived from former ones as an inductive process of learning. Inductive inference techniques, i.e. chunking, abstraction/specialization and simplification are particularly relevant to design knowledge acquisition (Tang, 2001). 
The difference between experts and novices is that experts are more knowledgeable about their domain. Their memory have an episodic component that encodes experience; facts are stored in a semantic mode in which they are defined by the role played in different situations. Experts' reasoning is based on cases rather than rules (Kolodner, 1983) and is more automatic and faster. This discussion about reasoning mechanisms of novices and experts is similar to the previous one on context. The proceduralized context can be viewed as a memory reorganization in which facts are rearranged accordingly episodes lived.

On the other hand, design tasks are normally ill-defined and incomplete. Thus, for fulfilling the requirements implicit in a task, a student or a novice needs help to turn explicit the contextual knowledge associated to the proposed situation. The lack of information found in all engineering projects is fulfilled by a human-human cooperative debate established between professionals, between students and the teacher, and among students as well, depending on the situation. This leads to the importance on helping participants in their argumentative processes.

\section{Cooperation and Learning}

The term computer supported cooperative work (CSCW) was coined in the late 80 's and encompassed a wide range of applications related to team working. The term "cooperative work" has been used to designate several work situations, all of them involving multiple individuals working together in a planned way and in tasks that are related together.

There is some argumentation that, in theory, all work is essentially cooperative or collaborative, but there is some agreement that "cooperative work" is a type of work that involves a set of relatively autonomous and non hierarchical coordinated activities, characterized by shared responsibilities. It is also referred as people engaged in incessant and direct communication performing tasks linked to the production of a particular product or service.

In contrast to the spontaneous linking of interrelated production processes, cooperative work relationships in design are characterized by being planned or rather premeditated (Bannon and Schmidt, 1991). In a design team participants are acquainted with design methodology and project goals, which define the accomplishment of some generic tasks to solve design problems (Chandrasekaran, 1988). Design tasks are linked to procedures, generally used by engineers as frames to construct a genuine strategy tailored to the specificity of a given situation. In this sense, there are some planned collective activities in a design team that are adapted for each case or each design step, doesn't mattering the nature or the type of the project.

Cooperative work comprises direct and indirect symbolic interactions, and distributed and collective modes of interaction as well. The tasks can be conducted in a distributed manner by semi-autonomous professionals that plan their own 
strategies and change their behavior as the circumstance's change, matching the situation found in a design team, in which participants have their own specialization (architecture, facilities, etc.) interconnected by the project goals and project constraints.

$\mathrm{CSCW}$ is an engineering discipline attempting to construct suitable systems for groups and organizations, and simultaneously, CSCW is a social science aiming at understand the basis for that construction in the social world (Ackerman, 2000). As stressed by Ackerman, there is a social-technical gap in CSCW, a mismatch between what is required socially and what can be done technically today. Among others, the author argued that systems are not able to capture nuances of the communication process and often assume a shared understanding of information, which is not found in groups with different backgrounds or belonging to different organizations. Without shared meanings and histories, meanings must be negotiated and information will loose context as it crosses boundaries.

The case of design teams in the AEC sector is slightly different, as participants have similar backgrounds, thus building an interpretative context of problems and crossing the border between different disciplines are part constituent of design tasks, and the key issues faced by engineers and architects. As already stressed, students have more difficulties in crossing the border as their perception of contextual knowledge is not straightforward, needing direct assistance to surpass these difficulties.

A design team is a group of experts in several domains cooperating in a common goal that needs a sort of functionality to enhance their work. The design arena, a place to set up collective activities, is much more an environment for negotiation of constraints and decision making, where the identification of the tasks and the relationships between them allow to tackle the domains and the role to be played by each participant. The routine issues addressed in supporting a team are how to manage and control the design information state, how to share the correct information and how to deliver design information in the correct time.

On the other hand, the generic situation experimented by engineers, architects and technicians during a project is not quite different from the ones faced by students engaged in an academic project. Normally, academic projects are assigned to a group of students aiming at developing teamwork skills within the group. Built shared meanings, surpass contextual divorces, identify common goals are the main problems faced by students when participating in a project. The role played by faculty in a design course is more like a "project leader" role, where a more experienced professional helps novices in decision-making and in negotiating conflicts.

Learning and cooperation are very close issues. Social-cultural theory stresses that social interactions that occur among peers, and between peers and somebody more experienced, promote learning. Learning takes place through verbal interactions and what is learned during the interactions would be used when the learner tries a similar problem independently. 
This belief is grounded in Vygotsky's theories that consider causal relationship between social interaction and the individual's cognitive development (Vigotsky, 1998). It is suggested that by interacting (directly or indirectly) with more mature peers or experts, students can probably display abilities ahead of those displayed on their own. Accordingly to Vygotsky, the difference between the knowledge derived from social interaction and knowledge achievable defines the "zone of proximal development".

This means that the cooperation processes established among participants enable knowledge to be shared and permit knowledge acquisition. Context is for us as a new variable in the learning process, i.e., the social and physical context in which learning takes place. As already argued, context can be seen as the collection of relevant conditions and surroundings influence that makes a situation unique and comprehensible. This is what is observed in design situations, where cooperation is viewed as a process of building and maintaining a shared conception of a problem, in which knowledge is learned in applied situations. Figure 1 illustrates the situation.

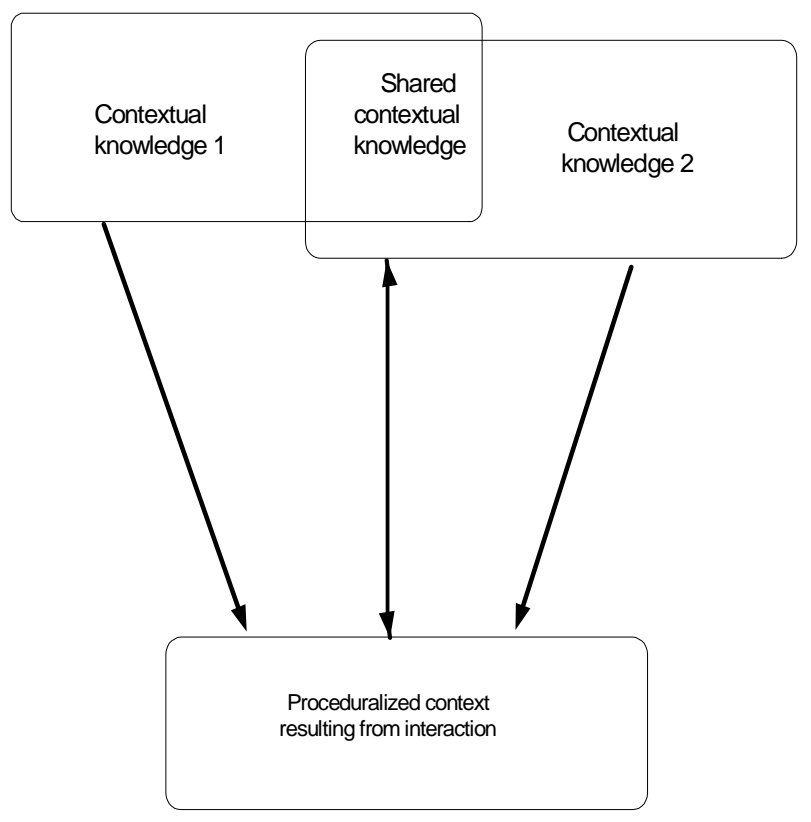

Figure 1. The building process of a shared conception of an artifact

The cognitive activities and communication processes of a group of students learning how to design a house and a team of professionals involved in a project share some common characteristics, although submitted to different constraints. Both situations involve people with different backgrounds in a common goal, the differences being the repertoire and contextual knowledge accumulated by each 
participant. In academic situations the teacher plays the role of a more experienced designer capable to establish a shared contextual knowledge with a student, enabling the "zone of proximal development" where apprenticeship takes place. In both situations there is an incremental knowledge acquisition as part constituent of the intellectual activity of designing.

\section{The design progression in the building industry}

The design progression in the Architecture, Engineering \& Construction sector (AEC) follows standards issued by the AEC associations, and professionals are acquainted about the steps needed to achieve a complete description of a building. They prepare some key documents at each step of the design progression and some documents must be presented to the local authorities to have a project approved.

The workflow in the AEC sector is very stable and well known. Building procedures are very well defined and the steps to be followed to complete a project are public domain among the AEC community. As already argued, the initial perception of a building structure is known and the disciplines involved in the building design process are already identified. Designing a building belongs to the class of routine design, where design strategies and plans to arrive to new solutions are already known. Engineers and architects use established procedures as frames to construct a genuine strategy tailored to the specificity of a given situation.

The organizational pattern of the AEC sector is not vertically integrated as it is observed in the manufacturing industry. In the AEC sector a cluster of companies take care of a contract, each company being responsible for part of the design progression. It is common to have companies involved only in some specialized portions of the project - as plumbing, structure, acoustics - and others that are responsible for the construction itself. There are also companies specialized in the quality control of the construction process. This specialization and fragmentation are typical of the AEC sector, which can be roughly described of a network of specialized companies that take care of part of the building process or develop a subsystem of the building. This division of labour occurs in the design phase and in the construction phase as well.

A similar situation is observed in engineering schools in which fragmentation among disciplines and divergent education is the dominant pattern (Frutcher, 1999). Confined disciplines exclude interactions and, during an engineering course, there is only a few number of opportunities to contextualize knowledge and practical apprenticeship. It is also argued that one of the reasons for this situation in the professional site is routed by the way education in AEC is structured today, by isolated disciplines (Frutcher, 1999). Engineers and architects reproduce in their professional life the way they have learned to make projects. 
All building projects share a core of explicit knowledge that represents the state of art in building design. This set of knowledge is comprised by the initial constraints imposed by the terrain, the legal constraints imposed by the city rules, and the current engineering practices adopted by professionals to find feasible solutions. Figure 2 shows the interaction between client and experts as a process influenced by explicit knowledge associated.

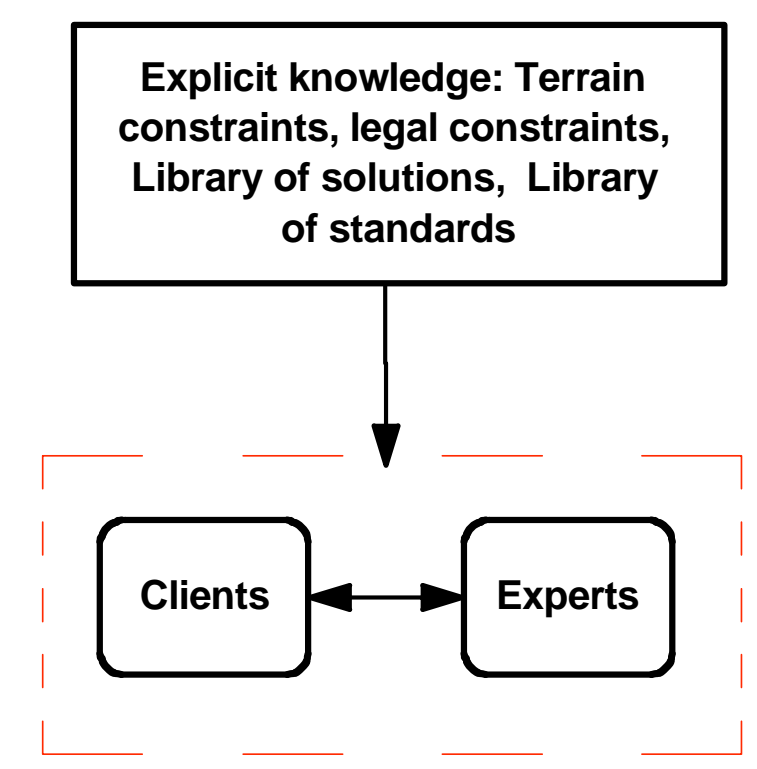

Figure 2. Types of explicit knowledge shared between clients and experts

The number of disciplines involved in the project of a building depends on the complexity of the building associated to its size and function. There is a continuum of complexity ranging from simple townhouses to intelligent high-rise buildings. In the AEC market, an entrepreneur, an individual or a company owner, is in charge of managing the total entrepreneurship. They play the role of coordinator and is under their responsibility make the contracts with professionals and specialized companies.

It is common sense in the AEC sector that there is a lack of integration between the several professionals that collaborate in a project. Besides this, there is no concern, during the design phase, on planning carefully the execution process of the design details. The application of special construction methods, the use of auxiliary equipments and the site layout are left to be decided by the contractor. The results are well known: reworking, penalties and other casualties that cause rising costs and delays in planned schedules. 
Workflow automation in the building industry is relatively easy and there are several commercial systems available in the market that manage the documentation and the related design activities ${ }^{1}$. These systems are designed for huge construction contracts as they provide a lot of functionality: schedule programming, cost control, documents management, task management, etc. These types of systems are normally used after the major design decisions were already done.

Some of these systems take advantage of the client-server technology and the $w_{e}{ }^{2}$, providing solutions very useful to partners involved in a construction contract or in a maintenance contract (Ganeshan et al., 2001). Therefore, in the initial steps of design progression the design requirements are incomplete and, to complete the fuzziness and arrive to a contingency solution, a negotiation process is established to arrive to decisions accepted by the team. There are only a few number of computer systems concerned in aiding design teams in the initial steps of the design process, which denotes the opportunity of this work applied to the building industry.

\section{The Atelier Projeto (SisPro) project}

The SisPro project is part of the conjoint activities that involve two Brazilian universities, and some medium-size building companies in the Juiz de Fora region. The SisPro project comprises a computer environment to aid a design team in a project and some experiments to evaluate the improvements achieved by teams in real design situations. The SisPro computer environment aims at supporting cooperation activities and learning processes that are launched when working in a team (Borges et al., 1999).

The project is under development, and some of its modules are part constituent of $\mathrm{Ph} . \mathrm{D}$. theses developed at the engineering graduate school of UFRJ. The project as a whole will be tested in an academic project that will be assigned to engineering and architecture students next year. Experiments including the participation of clients will be made with one medium-size building company in the project of a new building.

A "typical" workflow for building design is shown in figure 3 and the portion of the whole process that is related to the SisPro project is highlighted in a box. The activities shown represent the main steps in the design of a building.

\footnotetext{
1. ProjectNet (http://www.citadon.com), Prosys (http://www.prosys.fr), Primavera Expedition (http://www.primavera.com), all sites visited 08/09/2001.

2. Citywork, a cooperative system created for the Public Works Department at the Fort Gordon (GA) to support maintenance management.
} 


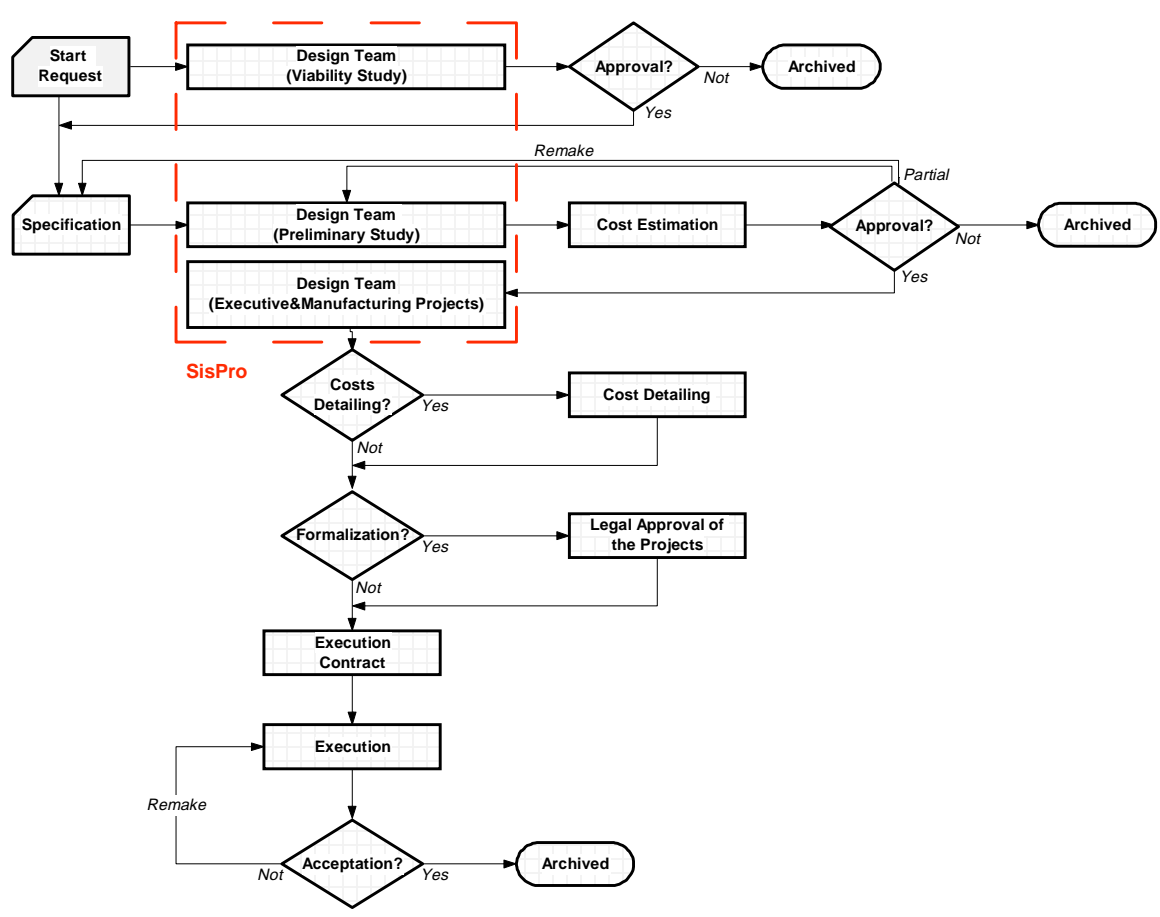

Figure 3. Workflow in the building industry

SisPro's portfolio includes a computer environment that aims at fulfilling two main goals: integrate relevant knowledge to design a building and develop teamwork skills among participants. The basic requirements that drove the development of this environment were: helping participants to structure contextual knowledge, permitting them to share their individual's tacit knowledge and proceed knowledge acquisition through interaction. The SisPro architecture is shown in figure 4 .

It takes advantage of client-server technology to allow virtual interaction during the project progression fulfilling the following demands:

- Allows a participant to create, view or modify documents associated with a project. This functionality is subjected to restrictions depending on the rights assigned to each participant;

- Allows participants being aware of changes made in documents accordingly to their areas of interest and role in the project;

- Supports asynchronous argumentation and sharing of visual and textual information. Visual information can be embedded to textual argumentation;

- Supports synchronous discussion; 
- Allows concurrent activities associated to a given task;

- Allows the identification and the structuration of contextual knowledge.

The SisPro environment comprises a set of functions to enable synchronous and asynchronous communication and interaction. There is a virtual workspace for each user that permits the communication among all professionals that are on-line, and a virtual workspace for each project that allows controlled communication among a project team.

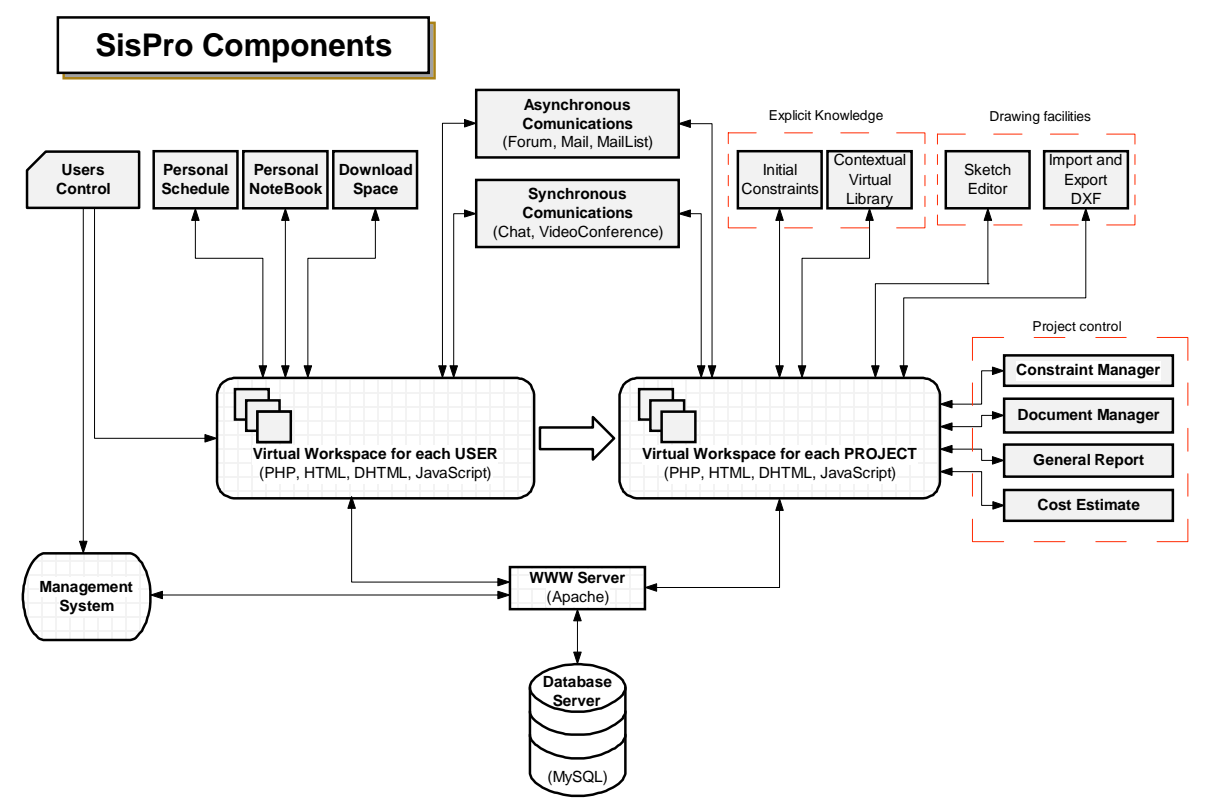

Figure 4. The SisPro architecture

Learning and knowledge acquisition take place through the interactions established within the team. The forum provided as part constituent of SisPro fulfils the need of communication between novices and more experienced people. It offers a collection of cooperation and communication mechanisms that clarify the argumentation that takes place in the design process. It allows the structuration of the design problems, the maintenance of consistency in decision-making, and keeping track of decisions. Besides this, argumentative processes are a powerful way of discovering the structure of wicked problems, as those presented in design.

Diagrammatic reasoning (Chandrasekaran, 1997) is embedded in SisPro permitting spatial argumentation to be integrated in the design discourse avoiding context divorce to arrive. It is argued that there is a contextual divorce if argumentation in design is not integrated with design spatial representation (Giboin, 
1999), (Shum, 2001). Giboin stresses that "without the ability to relate construction and argumentation to each other, discussing the solution is impossible. Without construction situations, design rationale cannot be contextualized". The integration between the main task and design conceptions discussed by participants is provided by SisPro, i.e., the graphical representations are attached to the arguments posted.

An example of SisPro screen is presented in figure 5, and on the foreground one can see a drawing edited by an image viewer being commented by two members of a design team. The background shows the personnel that are on-line at the moment.

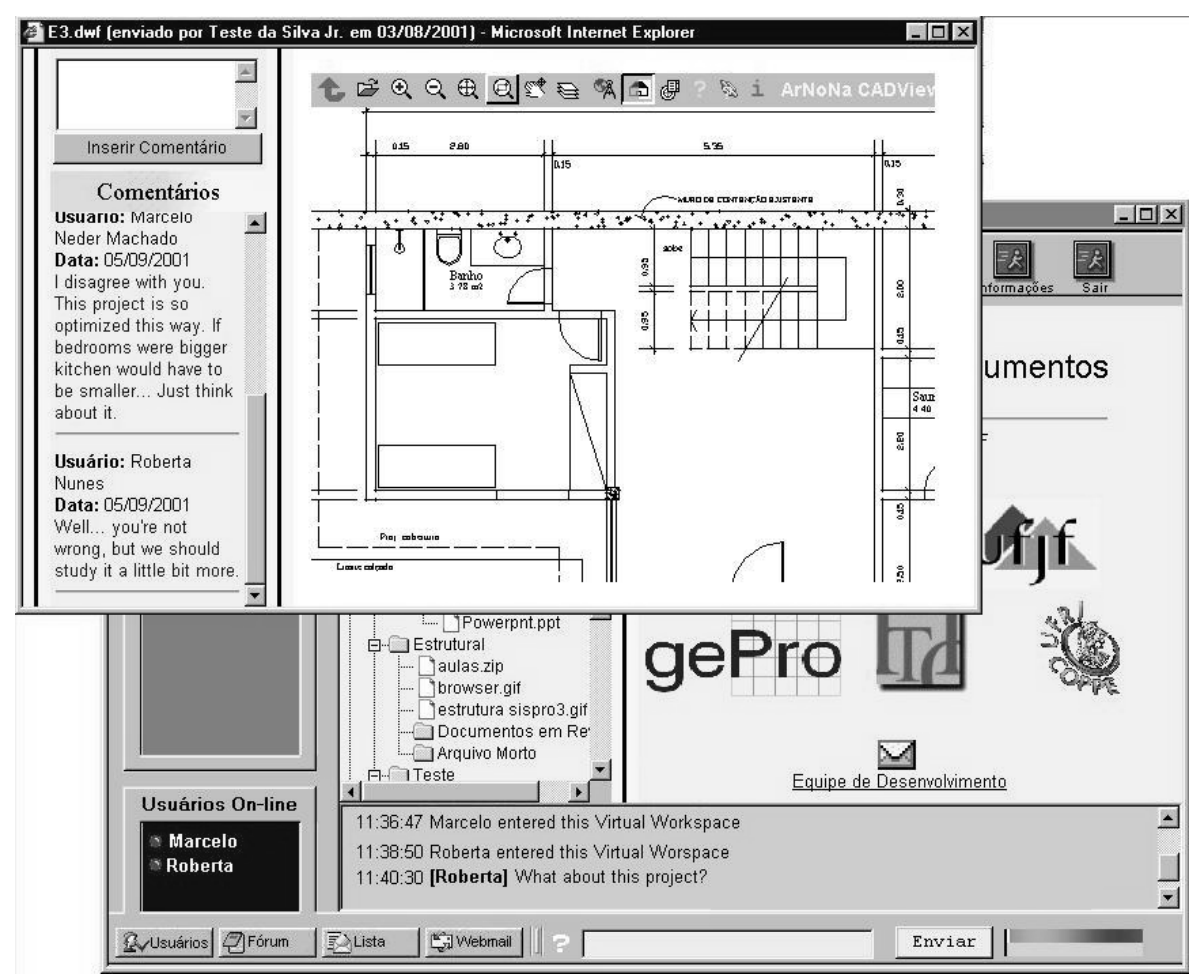

Figure 5. A SisPro screen

In addition, there is a collection of drawing facilities that fulfils the needs for each design step. There is a layout editor for rapid sketching of room distribution, a roof editor and other graphical editors tailored for specific needs of each design step. The other functions are related to control the release of documents and the project progression.

Explicit knowledge associated to building design and construction is packed in context sensitive libraries that permit users gather context knowledge that intervenes in the design of a building element. One of these libraries is the Architectural 
Contextual Library (ACL) that was conceived by considering three main building blocks: architectural elements, design concepts and design solutions (Naveiro et al., 2001). The first one is composed of the physical elements of a building, the second represents the articulation of the main elements with specific and typical situations and the third one presents some solutions that integrate the prior ones.

Architectural elements represent the common knowledge on functional elements of a building. It is the language that architects refer when naming parts of the whole, the declarative language that describes the general properties of architectural elements in a sharable way. The architectural elements share an encoded graphical language for spatial representation that is part of the architect repertoire (Lawson, 1997). They are the invariant portions of a building; every house has doors, windows, etc. Some architectural elements can be grouped by function, as follows: structural elements (columns, beams, slabs), insulation elements (walls, roofs) and horizontal and vertical circulation elements (stairways, ramps, corridors).

The second issue concerns the relationships between the architectural elements in applied situations. It is called design concepts, and embodies contextual knowledge related to constraints and requirements of each architectural element, associated to the spatial relations that must be established between them in order to have functional integrity. Each architectural element can be viewed from different contexts and textual and visual media explains the interdependency between them. This explanation corresponds to the part of the contextual knowledge invoked and situated within the problem at hand, which has been prior called the proceduralized context associated to the decision process.

The third issue is a set of best practices embodied in concluded projects, which reflects the articulation between the former two aspects and represent prototypical situations or instantiations for assigned problems. As already stressed, the process of proceduralization requires reasoning about causes and consequences that are experimented in case-based dissection. This module is called design solutions, and it is composed of explanation texts, raster images and vectorial drawings.

If we take as example the element "stairways" one can identify all declarative knowledge related to it, despite the type or style of the stairway chosen.

These pieces of knowledge are composed, for instance, by the number of steps needed for a given height, associated with the tread width and the riser height (figure 6). This type of information, associated to ergonomic and constructive aspects that define the comfort, cost and accessability of a stairway are available to designers and students as a means of a multi criterion approaching for the subject "stairways". 


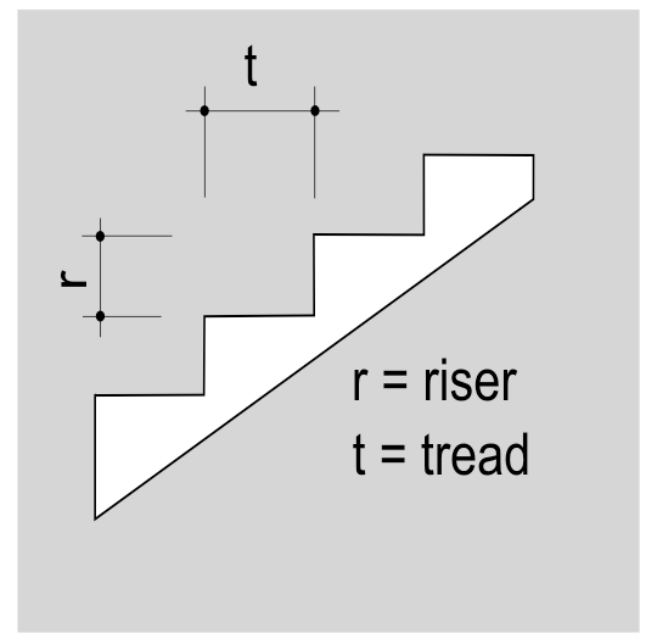

Figure 6. Geometric relations of a stairway step

As stressed by Karsenty and Brezillon, "explanation must be conceived of as part of a cooperative problem solving process and not just a parallel phenomenon that does not modify the course of the reasoning" (Karsenty and Brézillon, 1995). The process of explanation should be viewed as a negotiation of meaning, i.e., accordingly with the situated cognition approach, in which the design rationale is learned in applied situations.

The role played by stairways in a project is very complex as it is related directly with the circulation paths of people in a building and with the architect intentions in fulfilling the space. There are several types of stairways (straight run, U-type, Ltype, spiral, etc.) and they can be treated differently by the architect. They can be additive, they can follow the edge of a stage, or they can just fulfil an empty volume.

In the Architectural Contextual Library, this knowledge about stairways is grouped under design concepts and is presented as partial solutions where the attribute at hand is highlighted. Hypertext format is used to allow the designer or student built his personal learning process, beginning by identifying relevant knowledge that is needed.

\section{Conclusions}

The introduction of web-based cooperation systems and tools represents a technology innovation in engineering education and in professional practices as well. Companies are increasingly distributed worldwide. Projects are shared between companies and their suppliers, associated to the improving performance of 
Internet applications and decreasing costs in Internet connection reinforce the opportunity on exploring Internet possibilities in design and education.

Designing and learning are both social processes, in which social interactions arising among participants promote learning. The design process encompasses a set of intellectual activities concerned with problem solving and negotiation processes among participants. Individual decisions must be validated and integrated with the collective constraints that dynamically change during design progression. The design process is also recursive, there is a need in keeping tracking on decisions to follow new routes or choose different conceptions. This is one of the features of SisPro, to permit the recording of the argumentation processes that take place and the assumptions considered in making a decision.

Seeking for information and learning is part constituent of the design process, as finding new solutions involves the search and acquisition of new knowledge pieces. This matches an important feature provided by the SisPro environment, a module called contextual libraries, in which contextual knowledge can be invoked and situated within the problem at hand.

The SisPro environment represents an effort in retrieving the ancient "atelier" concept, the traditional learning space in which people were bring together to engineering \& architectural practice. It is a model to bring together the $\mathrm{A} / \mathrm{E} / \mathrm{C}$ disciplines that intervene in a building project taking advantage of information technology enabling people to interact and to cooperate in a common goal.

Computer support for cooperative teamwork in design is still in the early stages of development. Robust integrated seamless systems linked to current commercial applications are not available today, confirming that this is a subject that needs major developments in the industry and needs standards for interoperability. The next issue is integrating the SisPro environment for remote collaboration into current engineering education. It is planned an academic test in the beginning of 2002 and SisPro will be assessed and validated within the engineering curriculum.

\section{Acknowledgments}

This work is part constituent of a conjoint research project involving the Universidade Federal do Rio de Janeiro (UFRJ) and the Université Pierre et Marie Curie. This project has been supported by the Fundação Coordenação de Aperfeiçoamento de Pessoal de Nível Superior (CAPES) and the Comité français d'évaluation de la coopération universitaire avec le Brésil (COFECUB). The participation of Prof. Ricardo Naveiro as visiting researcher at LIP6 for 2001 was fully supported by CAPES. 


\section{References}

Ackerman M., "The Intellectual Challenge of CSCW: The gap between social requirements and technical feasibility", Human-Computer Interaction, Vol. 15, 2000, 179-203.

Anderson J., Language, Memory and Thought, New Jersey, Erlbaum, 1995.

Borges M., Naveiro R., Souza Fillho R., "SISPRO - A Computer Support System for conceptual design in architecture", Proceedings of the $12^{\text {th }}$ International Conference in Engineering Design, aug. 1999, Munich, Heurista.

Bannon L. and Schmidt K., "CSCW: Four Characters in Search for a Context", Studies in Supported Cooperative Work, Bowers J. \& Benford S. (editors), Elsevier, 1991, pp. 3-16.

Brézillon P. Context in problem solving: A survey, The Knowledge Engineering Review, 1999, 14(1), 1-34.

Brézillon P. and Pomerol J.-Ch., "Contextual knowledge sharing and cooperation in intelligent assistant systems", Le Travail Humain, Vol. 62, No. 3, Paris, 1999, pp. 223246.

Brézillon P. and Pomerol J.-Ch., "About some relationships between knowledge and context", Proceedings of the $3^{\text {rd }}$ International Conference on Modeling and Using Context, Dundee, july 2001, pp. 461-464.

Brown J.S. and Duguid P., "Organizational learning and communities of practice: towards a unified view of working, learning and organization", Organization Science, Vol. 2, No. 1, 1999, pp. 40-57.

Bucciarelli L., "An ethnographic perspective on engineering design", Design Studies, Vol. 9, No. 3, 159-168.

Bucciarelli L., Designing Engineers, Cambridge, The MIT Press,1994.

Chandrasekaram B., "Generic tasks as building blocks for knowledge-based systems: the diagnosis and routine design examples", The Knowledge Engineering Review, 1988, Vol. 3, No. 3.

Chandrasekaram B., "Diagrammatic representation and reasoning: some distinctions", AAAI Fall 97 Symposium Series, Boston, 1997, pp. 1-5.

Clancey W.J., "Practice cannot be reduced to theory: knowledge, representations and change in the workplace", Organizational Learning and Technological Change, S. Bagnara, Zuccermaglio C. and Stucky S. (eds), 1995, Berlin, Springer, pp. 16-46.

Frutcher R., "A/E/C Teamwork: A Collaborative Design and Learning Space", Journal of Computing in Civil Engineering, Vol. 15 No. 1, 1999, pp. 261-269.

Frutcher R. \& Emery K., "Teamwork: Assessing Cross-Disciplinary Learning", Proceedings of the Computer Support for Collaborative Learning Conference, Palo Alto, dec.1999, Lawrence Erlbaum Associates, pp. 1-11.

Ganeshan R., Grobler F., Wang C. and Coimbatore V., "CITYWORK: Application of Collaborative Technologies for Infrastructure Management", Journal of Computing in Civil Engineering, 2001, 15(1), pp. 74-80. 
Giboin A., "Contextual Divorces: Towards a framework for identifying critical context issues in collaborative-argumentation system design", Modeling and Using Context, Trento, sept. 1999, Berlin, Springer, pp. 471-474.

Karsenty L. and Brézillon P., "Cooperative problem solving and explanation", Expert Systems with Applications, Vol. 8, No. 4, 1995, pp. 445-462.

Lawson B., Design in Mind, Oxford/UK, Architectural Press, 1997.

Kolodner J., "Towards an understanding of the role of experience in the evolution from novice to expert", International Journal of Man-Machine Studies, Vol. 19, 1983, pp. 497518.

Naveiro R., "The role of computer support for integrated product design", Proceedings of the XI International Conference on Engineering Design, Tampere, aug. 1997, A.Riitahuhta, pp. 465-468.

Naveiro R., Brézillon P. \& Borges M., "Learning in Context: Contextual Libraries in Architecture Distance Education", Anais do XII Simpósio Brasileiro de Informática na Educação, Vitória, Nov. 2001.

Naveiro R. \& Oliveira V., O projeto de engenharia, arquitetura e desenho industrial, Juiz de Fora/MG, Editora da Universidade Federal de Juiz de Fora, 2001.

Nonaka I. and Takeuchi H., The knowledge-creating company, New York, Oxford University Press, 1995.

Shum S., MacLean A., Bellotti V., Hammond N., "Graphical Argumentation and Design Cognition", Human- Computer Interaction, Vol. 12, No. 3, 2001, pp. 267-300.

Smith R. and Farquhar A., "The road ahead knowledge management: an AI perspective", AI Magazine, Vol. 21, No. 4, 2000, pp. 17-40.

Tang M., "Inductive learning techniques in design process: a design concept learning system", Integrated Computer-Aided Engineering, Vol. 8, 2001, pp. 171-186.

Vigotsky, L. Mind in Society: The Development of Higher Psychological Processes. Cambridge, Harvard University Press, 1978.

Wenger E. Communities of practice, New York, Cambridge University Press, 1998.

Zacklad M. \& Grundstein M., Management des Connaissances: Modèles d'entreprise et applications, Paris, Hermes, 2001. 